\title{
ORIGINAL
}

ARTICLES

\section{Attitudes Toward Family Medicine Among Students Choosing Other Primary Care Specialties}

Jacob Prunuske, MD, MSPH; Hana Kang; Andrea Wendling, MD; Jennifer Edwards-Johnson, DO, MPH; Julie P. Phillips, MD, MPH

\begin{abstract}
BACKGROUND AND OBJECTIVES: Little is known about how medical students choose between primary care specialties. We compared the attitudes toward family medicine of medical students intending to practice primary care but not family medicine (PCNFM), with students intending to practice family medicine (FM) and those intending nonprimary care (NPC) careers.
\end{abstract}

METHODS: The Family Medicine Attitudes Questionnaire (FMAQ) was distributed to 2,644 fourth-year medical students at 16 medical schools in spring 2017. Respondents were stratified by career intention. In this secondary data analysis, we used descriptive statistics to characterize responses to each questionnaire item and FMAQ total score, and analysis of variance with Bonferroni post hoc analyses to compare category and item mean responses.

RESULTS: Of 2,644 fourth-year medical students who received the FMAQ, $1,188(41.8 \%)$ submitted usable responses. The 14-item FMAQ has a maximum score of 70 . Mean total scores differed by category: 59.05 for FM, 52.88 for NPC, and 54.83 for PCNFM $(F=108.96, P<.01)$; the differences between each possible pairing were significant $(P<.05)$. Comparing the responses of students intending PCNFM careers with those of students intending NPC careers, there were no differences in mean responses for 8 of 14 FMAQ items. Responses of students intending PCNFM careers were similar to students intending FM for only 4 of 14 items $(P<.05)$.

CONCLUSIONS: Fourth-year students intending to match into PCNFM have attitudes toward FM that more closely approximate the attitudes of NPC students than the attitudes of FM students. Future research should explore implications for curricular development, student mentorship, and career advising.

(Fam Med. 2020;52(7):491-6.)

doi: 10.22454/FamMed.2020.342498

D ecades of research consistently shows that health outcomes improve with an increasing supply of primary care physicians. ${ }^{1-8}$ In the United States, primary care is commonly associated with the specialties of general internal medicine, general pediatrics, and family medicine. ${ }^{9}$ Sometimes, rics are included as primary care closely mirrors the distribution of the US population. ${ }^{10}$

The United States is experiencing current and projected primary care shortages related to both physician workforce composition and geographic distribution of practicing clinicians. ${ }^{11,12}$ Further, because the population is aging and the prevalence of chronic illness among adults has increased, the shortage of primary care providers for adults is particularly important. ${ }^{12}$ Over the past 4 decades, fewer than half of internal medicine physicians remained generalists and now nearly $90 \%$ choose subspecialty practices. ${ }^{13}$ While the supply of generalist pediatricians is projected to be stable at the national level, ${ }^{14}$ there are projected regional pediatric workforce deficits. ${ }^{15} \mathrm{Be}$ cause of these factors, increasing the proportion of students who choose family medicine may be the most efficient way to optimize the US primary care physician workforce.

Most students choosing family medicine careers practice primary care, ${ }^{16}$ however, many medical students who intend to practice primary care choose other specialties, particularly internal medicine, internal ciplines, however, family medicine is the only one of these specialties that provides comprehensive care for all patients regardless of age or gender. Among physician specialties, the distribution of family physicians most
From Medical College of Wisconsin - Central Wisconsin, Wasau, WI (Dr Prunuske); Michigan State University College of Education East Lansing, MI (Ms Kang); and Michigan State University College of Human Medicine, East Lansing, MI (Drs Wendling, Edwards-Johnson, and Phillips). 
medicine-pediatrics, and pediatrics, and are thus less likely to ultimately practice primary care.

Little is known about how students choose between primary care specialties, but one study suggests that students make decisions based on their preferred patient population and the specialty's approach toward patient care. ${ }^{17}$ Students interested in primary care may share characteristics that differ from other students, such as lower family socioeconomic status, origination from rural or other underserved areas, nontraditional routes to medical school, or identification as members of racial minority groups ${ }^{18}$; these personal characteristics could also contribute to similar attitudes toward primary care for such students. At the same time, student specialty preference for family medicine varies at medical school matriculation, and may also be influenced by the medical school curriculum, family medicine interest group participation, and other institutional characteristics. ${ }^{19}$ We sought to understand the attitudes toward family medicine of fourth-year medical students who intend to practice primary care, but not family medicine. Specifically, we aimed to identify whether these students' attitudes toward family medicine closely align with students intending family medicine (FM), or more closely align with students planning a nonprimary care practice. We hypothesized that because these students intend to practice primary care, they would have a similarly positive attitude toward primary care as the students planning FM careers, and thus a positive attitude toward family medicine as well.

\section{Methods}

The Family Medicine Attitudes Questionnaire (FMAQ) was distributed to 2,644 fourth-year medical students at 16 medical schools in the spring of 2017. Details on the questionnaire development, validation, and respondent demographics have been previously published. ${ }^{20,21}$ The FMAQ consists of 14 statements that describe attitudes toward family medicine. The questionnaire tasked respondents with rating their level of agreement with each statement using a 5-point scale. It also asked respondents to select one of three choices for the specialty area of medicine they planned to practice: (1) family medicine (FM), (2) nonprimary care (NPC), or (3) primary care, but not family medicine (pediatrics, internal medicine, or med-peds with a primary care focus [PCNFM]). For this secondary data analysis, we stratified respondents by career intention into these three categories. We used descriptive statistics to characterize responses to each questionnaire item and FMAQ total score, and analysis of variance with Bonferroni post hoc analyses (to adjust for multiple comparisons) to compare total and item mean responses. The Medical College of Wisconsin Institutional Review Board determined this study was exempt from review.

\section{Results}

Of 2644 fourth-year medical students who received the questionnaire, $1,143(43.2 \%)$ submitted usable responses; 238 (20.8\%) intended to match in FM, 670 (58.6\%) in NPC, and $235(20.6 \%)$ in PCNFM. The 14item FMAQ has a maximum score of 70. Mean total scores differed by career intention: 59.05 for FM, 52.88 for NPC, and 54.83 for PCNFM $(F=108.96, P<.05)$ and the differences between each possible pairing were significant $(P<.01)$. See Figure 1 for boxplot comparisons of mean total scores between groups. While the responses of students intending FM careers were different from those of students intending NPC careers for all 14 items $(P<.05)$, the responses of students intending PCNFM careers more closely approximated the responses of students intending NPC than those of students intending FM. Specifically, comparing the responses of students intending $\mathrm{PC}$ NFM careers with those of students planning NPC careers, there were no differences in mean responses for 8 of 14 FMAQ items $(P<.05$, Table 1$)$. Comparing the responses of students intending PCNFM with those of students intending FM, there were no differences in mean responses for 4 of 14 items $(P<.05$, Table 2$)$. Table 3 shows details of the comparisons of mean item responses by career intention for all groups.

\section{Discussion}

The attitudes toward family medicine of fourth-year students entering the Match vary significantly by career intention. Predictably, students intending to match into family medicine have the most positive attitudes toward family medicine and those intending nonprimary care fields have the least positive attitudes toward family medicine. Fourth-year students intending to practice primary care, but not family medicine, have attitudes that more closely approximate the attitudes of students intending to match into nonprimary care fields than they do the attitudes of students intending to match into family medicine.

This finding may contribute to the relative paucity of students who match into internal medicine who actually practice primary care ${ }^{16} \mathrm{We}$ did not ask students intending PCNFM careers to identify their specialty of choice, so we cannot further evaluate this possibility with this study's data. Future research could explore attitudes toward family medicine among internal medicine and pediatric residents over time to understand these attitudes better and assess for relationships between attitudes toward family medicine and choice to enter a subspecialty fellowship.

These findings have implications for faculty, advisors, and schools as they develop strategies for family medicine interest group (FMIG) activities and family medicine clerkship curricula. In particular, it is possible that experiences focused around the seven items of the FMAQ where student attitudes toward family medicine were not significantly different among NPC and PCNFM 
Figure 1: Comparison of Mean Total Score by Career Intention

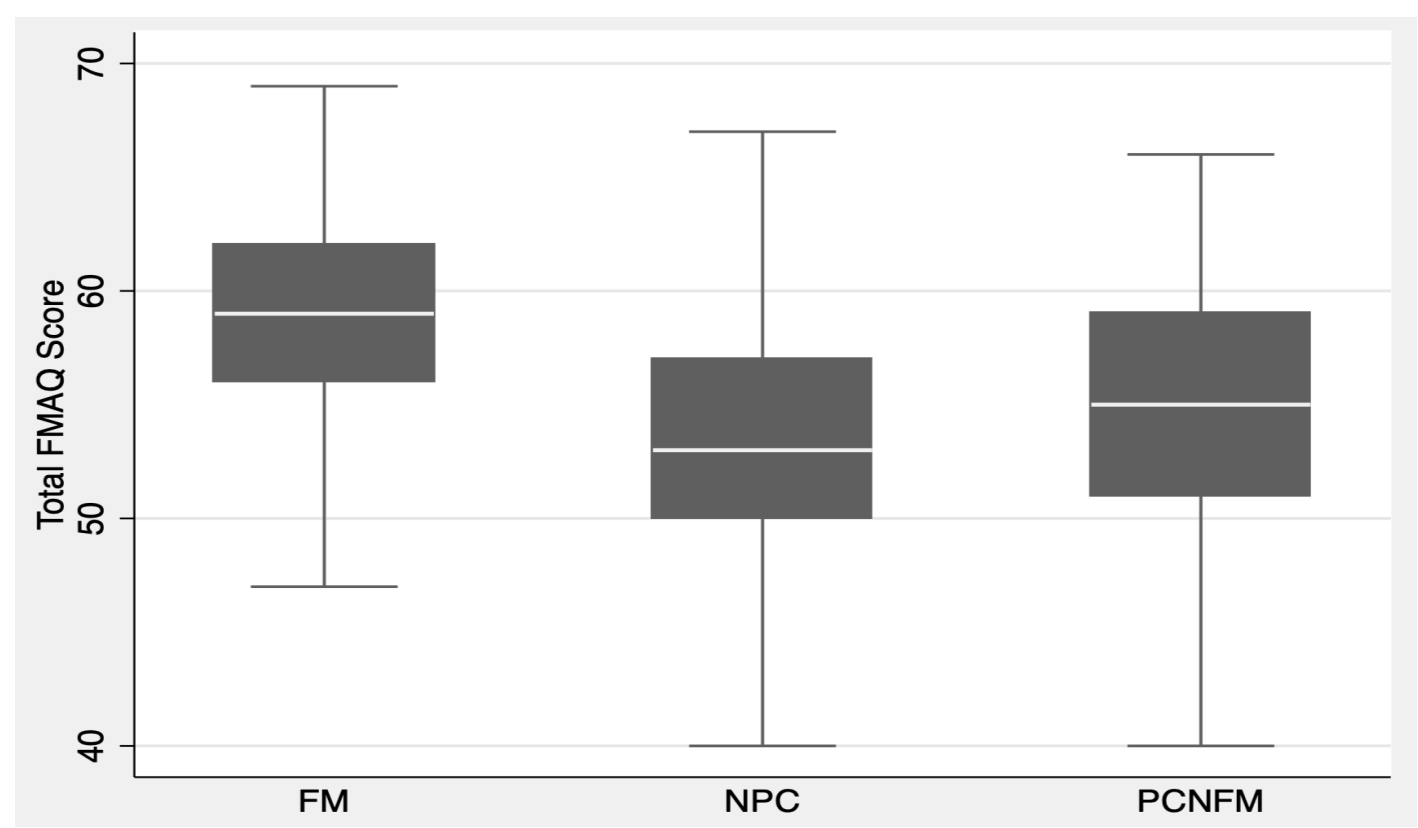

This boxplot identifies median total FMAQ score (white line), the interquartile range (box), the maximum observation value below the 75 th percentile $+1.5 *$ interquartile range (upper whisker), and the minimum observation value above the 25 th percentile $+1.5 *$ interquartile range (lower whisker).

Abbreviations: FMAQ, Family Medicine Attitudes Questionnaire; FM, family medicine; NPC, nonprimary care; PCNFM, primary care but not family medicine.

Table 1: Items Where Attitudes Toward Family Medicine Among Students Choosing Primary Care, but Not Family Medicine Are Indistinguishable From Attitudes of Students Choosing Nonprimary Care Careers

Family physicians provide only a small fraction of all health care delivered in the United States.

Family physicians can usually decide how much they want to work.

Family medicine requires knowledge that a subspecialist practice may not.

The United States has a very serious shortage of primary care physicians.

Family medicine provides a physician with enough income to live well.

The US health care system can only work well with family physicians playing an integral part.

Research to improve health happens very often in primary care settings.

Family physicians enjoy their work.

Table 2: Items Where Attitudes Toward Family Medicine Among Student Choosing Primary Care, but Not Family Medicine Are Indistinguishable From Attitudes of Students Choosing Family Medicine

The United States would provide better for its people if more medical students chose primary care.

To give good care, it is important to consider each patient in the context of his or her family.

The United States has a very serious shortage of primary care physicians.

In the United States, people don't rely on family physicians when they are very sick. 
Table 3: Comparison of Mean Total Score and Item Response by Career Intention

\begin{tabular}{|c|c|c|c|c|c|}
\hline Item & Group & Mean & SD & $\boldsymbol{F}$ & Bonferroni** \\
\hline \multirow{3}{*}{ Total score } & FM (1) & 59.04 & 5.08 & \multirow{3}{*}{$108.96^{*}$} & \multirow{3}{*}{$2<3<1$} \\
\hline & Non-PC (2) & 52.88 & 5.62 & & \\
\hline & PC, but not FM (3) & 54.82 & 5.44 & & \\
\hline \multirow{3}{*}{$\begin{array}{l}\text { Family physicians provide only a small fraction } \\
\text { of all health care delivered in the United States } \\
\text { (R) }\end{array}$} & FM (1) & 4.36 & 0.75 & \multirow{3}{*}{$11.83^{*}$} & \multirow{3}{*}{$(3=2)<1$} \\
\hline & Non-PC (2) & 4.09 & 0.80 & & \\
\hline & PC, but not FM (3) & 4.03 & 0.91 & & \\
\hline \multirow{3}{*}{$\begin{array}{l}\text { Family physicians can usually decide how much } \\
\text { they want to work. }\end{array}$} & FM (1) & 3.52 & 0.85 & \multirow{3}{*}{$12.65^{*}$} & \multirow{3}{*}{$(3=2)<1$} \\
\hline & Non-PC (2) & 3.19 & 0.93 & & \\
\hline & PC, but not FM (3) & 3.17 & 0.94 & & \\
\hline \multirow{3}{*}{$\begin{array}{l}\text { The United States would provide better for its } \\
\text { people if more medical students chose primary } \\
\text { care. }\end{array}$} & FM (1) & 4.48 & 0.69 & \multirow{3}{*}{$40.52^{*}$} & \multirow{3}{*}{$2<(1=3)$} \\
\hline & Non-PC (2) & 3.96 & 0.91 & & \\
\hline & PC, but not FM (3) & 4.32 & 0.78 & & \\
\hline \multirow{3}{*}{$\begin{array}{l}\text { To give good care, it is important to consider } \\
\text { each patient in the context of his or her family. }\end{array}$} & FM (1) & 4.57 & 0.58 & \multirow{3}{*}{$15.6^{*}$} & \multirow{3}{*}{$2<(1=3)$} \\
\hline & Non-PC (2) & 4.31 & 0.70 & & \\
\hline & PC, but not FM (3) & 4.46 & 0.60 & & \\
\hline \multirow{3}{*}{$\begin{array}{l}\text { Family medicine requires knowledge that a } \\
\text { subspecialist practice may not. }\end{array}$} & FM (1) & 4.50 & 0.59 & \multirow{3}{*}{$19.36^{*}$} & \multirow{3}{*}{$(3=2)<1$} \\
\hline & Non-PC (2) & 4.14 & 0.82 & & \\
\hline & PC, but not FM (3) & 4.15 & 0.80 & & \\
\hline \multirow{3}{*}{$\begin{array}{l}\text { The United States has a very serious shortage } \\
\text { of primary care physicians. }\end{array}$} & FM (1) & 4.53 & 0.63 & \multirow{3}{*}{$7.17^{*}$} & \multirow{3}{*}{$2<1,1=3,2=3$} \\
\hline & Non-PC (2) & 4.33 & 0.71 & & \\
\hline & PC, but not FM (3) & 4.41 & 0.63 & & \\
\hline \multirow{3}{*}{$\begin{array}{l}\text { Research-oriented students should probably not } \\
\text { consider family medicine careers. }(\mathrm{R})\end{array}$} & FM (1) & 3.80 & 0.87 & \multirow{3}{*}{$26.48^{*}$} & \multirow{3}{*}{$2<3<1$} \\
\hline & Non-PC (2) & 3.26 & 1.04 & & \\
\hline & PC, but not FM (3) & 3.46 & 0.96 & & \\
\hline \multirow{3}{*}{$\begin{array}{l}\text { Family medicine provides a physician with } \\
\text { enough income to live well. }\end{array}$} & FM (1) & 4.20 & 0.85 & \multirow{3}{*}{$29.85^{*}$} & \\
\hline & Non-PC (2) & 3.64 & 1.00 & & $(3=2)<1$ \\
\hline & PC, but not FM (3) & 3.78 & 0.92 & & \\
\hline & FM (1) & 4.54 & 0.68 & & \\
\hline $\begin{array}{l}\text { The US health care system can only work well } \\
\text { with family physicians playing an integral part. }\end{array}$ & Non-PC (2) & 4.22 & 0.73 & $19.44^{*}$ & $(3=2)<1$ \\
\hline & PC, but not FM (3) & 4.19 & 0.76 & & \\
\hline & FM (1) & 3.79 & 0.88 & & \\
\hline $\begin{array}{l}\text { Research to improve health happens very often } \\
\text { in primary care settings. }\end{array}$ & Non-PC (2) & 3.48 & 0.84 & $11.16^{*}$ & $(3=2)<1$ \\
\hline & PC, but not FM (3) & 3.59 & 0.87 & & \\
\hline & FM (1) & 4.42 & 0.65 & & \\
\hline $\begin{array}{l}\text { Family physicians work is complex and } \\
\text { interesting. }\end{array}$ & Non-PC (2) & 3.14 & 1.10 & $151.59 *$ & $2<3<1$ \\
\hline & PC, but not FM (3) & 3.67 & 0.89 & & \\
\hline & FM (1) & 3.67 & 0.98 & & \\
\hline $\begin{array}{l}\text { In the United States, people don't rely on family } \\
\text { physicians when they are verv sick. }(R)\end{array}$ & Non-PC (2) & 3.31 & 1.10 & $10.85^{*}$ & $2<(1=3)$ \\
\hline & PC, but not FM (3) & 3.52 & 1.02 & & \\
\hline
\end{tabular}


Table 3: Continued

\begin{tabular}{|c|c|c|c|c|c|}
\hline Item & Group & Mean & SD & $\boldsymbol{F}$ & Bonferroni* * \\
\hline \multirow{3}{*}{$\begin{array}{l}\text { Knowledge of family interactions is important } \\
\text { in treating individual patients. }\end{array}$} & FM (1) & 4.50 & 0.57 & \multirow{3}{*}{$23.42^{*}$} & \multirow{3}{*}{$2<3<1$} \\
\hline & Non-PC (2) & 4.17 & 0.67 & & \\
\hline & PC, but not FM (3) & 4.29 & 0.59 & & \\
\hline \multirow{3}{*}{ Family physicians enjoy their work. } & FM (1) & 4.15 & 0.66 & \multirow{3}{*}{$37.32^{*}$} & \multirow{3}{*}{$(3=2)<1$} \\
\hline & Non-PC (2) & 3.69 & 0.72 & & \\
\hline & PC, but not FM (3) & 3.80 & 0.69 & & \\
\hline
\end{tabular}

$* P<.01$

** Bonferroni test is significant at $P<.05$. For purposes of reporting, "<" and ">" represent significant differences; "=" represents no significant difference between groups.

Abbreviations: PCNFM, primary care but not family medicine; FM, family medicine; NPC, nonprimary care; R, reverse coded.

students (Table 1), may have the most potential to positively influence student attitudes toward family medicine. For example, pairing students who are interested in primary care with family physicians who clearly enjoy their work may help influence student choice of family medicine. Similarly, a panel discussion of family physicians discussing lifestyle and work hours may have potential to positively influence student attitudes toward family medicine. Family medicine faculty should also seek to explore student attitudes in these areas as they mentor and advise individual students. As students explore different professional identities, those aspects that are nurtured and supported by advisors and institutions will grow, and those that are discouraged or ignored will shrink..$^{22}$ Advising to sustain student interest in family medicine, as opposed to other primary care specialties, may be more effective if it attends to those areas where PCNFM students look more like NPC students than those intending family medicine careers.

This study is limited by the original data collection, which only measured fourth-year students, and only included one osteopathic institution. The applicability of these results to osteopathic students and to all medical students at earlier stages of training is unknown and warrants further study. The FMAQ has been validated for distinguishing attitudes toward family medicine among students intending family medicine careers from attitudes toward family medicine among students not intending family medicine, but the instrument's ability to distinguish between students intending PCNFM careers and NPC careers has not been studied.

The wording of the survey tool itself may have also impacted student responses. Individual survey questions reference family medicine physicians, primary care physicians, or a context of care independent of discipline. Based on the language used, items may have been viewed more or less favorably by respondents, rather than in the intended context. In addition, some students may have interpreted questions such as "Family physicians' work is complex and interesting" as exclusionary to other specialties, although this interpretation was not noted by student respondents when the instrument was pilot tested. ${ }^{20,21}$ Respondents may also have responded negatively to questions about family medicine because of annoyance at the questionnaire's focus on family medicine, or a desire to affirm their own specialty choices. Further qualitative study of the attitudes of students who intend PCNFM careers may help us better understand their perceptions and attitudes.
Strengths of this study included the relatively large sample size and use of a questionnaire validated for measuring medical student attitudes toward family medicine. This research has the potential to meaningfully contribute to the America Needs More Family Doctors: 25 x 2030 Initiative to increase the proportion of United States medical school graduates choosing family medicine. Future research could use the FMAQ to assess the impact of interventions designed to influence student attitudes toward family medicine, and should also explore the applicability of the FMAQ in other settings and populations.

In conclusion, this study provides valuable information about attitudes toward family medicine among students who choose other primary care specialties, intending to practice primary care. It has implications for faculty, advisors, and schools interested in specialty choice, FMIG activities, family medicine curricula, and student career advising. Faculty, advisors, and schools may use these findings to design different approaches and activities to increase the proportion of US medical students choosing family medicine, advancing progress toward the 25 x 2030 goal.

CORRESPONDING AUTHOR: Address correspondence to Dr Jacob Prunuske, Medical College of Wisconsin - Central Wisconsin, 1900 Westwood Dr, Suite 3100, Wausau, WI 544014106. 715-870-0910. 


\section{References}

1. Shi $\mathrm{L}$. The relationship between primary care and life chances. J Health Care Poor Underserved. 1992;3(2):321-335.

2. Shi L. Primary care, specialty care, and life chances. Int J Health Serv. 1994;24(3):431-458.

3. Vogel RL, Ackermann RJ. Is primary care physician supply correlated with health outcomes? Int J Health Serv. 1998;28(1):183-196.

4. Shi L, Starfield B. Primary care, income inequality, and self-rated health in the United States: a mixed-level analysis. Int J Health Serv. 2000;30(3):541-555.

5. Shi L, Starfield B, Kennedy B, Kawachi I. Income inequality, primary care, and health indicators. J Fam Pract. 1999;48(4):275-284.

6. Starfield B. New paradigms for quality in primary care. Br J Gen Pract. 2001;51(465):303309

7. Starfield B, Shi L, Grover A, Macinko J. The effects of specialist supply on populations' health: assessing the evidence. Health Aff (Millwood). 2005;24(Suppl Web Exclusives):W5-97-W5-107.

8. Basu S, Berkowitz SA, Phillips RL, Bitton A Landon BE, Phillips RS. Association of Primary Care Physician Supply With Population Mortality in the United States, 2005-2015. JAMA Intern Med. 2019;179(4):506-514.

9. Weiner JP, Starfield BH. Measurement of the primary care roles of office-based physicians. Am J Public Health. 1983;73(6):666-671.

10. Agency for Healthcare Research and Quality. Primary Care Workforce Facts and Stats No. 3. AHRQ Publication No. No. 12-P001-1EF. https://www.ahrq.gov/research/findings/ factsheets/primary/pcworkforce/index.html. Rockville, MD: AHRQ; 2012. Accessed February 11, 2020.
11. Dall T, Reynolds R, Jones K, et al. 2019 Update: The Complexities of Physician Supply and Demand: Projections from 2017 to 2032 Final Report. Washington, DC: Association of American Medical Colleges; 2019. https://aamcblack.global.ssl.fastly.net/production/media/ filer public/31/13/3113ee5c-a038-4c16-89af294a69826650/2019_update_-_the_complexities_of_physician_supply_and_demand - projections_from_2017-2032.pdf. Accessed February 11,2020

12. Wilkinson E, Bazemore E, Jabbarpour Y. Ensuring primary care access in states with an aging family physician workforce. Am Fam Physician. 2019;99(12):743.

13. Dalen JE, Ryan KJ, Alpert JS. Where have the generalists gone? They became specialists, then subspecialists. Am J Med. 2017;130(7):766-768.

14. Health Resources and Services Administration. Health Workforce Projections: General Pediatricians. Bethesda, MD: HRSA; 2017. https://bhw.hrsa.gov/sites/default/files/bhw/ health-workforce-analysis/research/projections/ PediatricianFS_51817.pdf. Accessed February 11,2020

15. Health Resources and Services Administration National and Regional Projections of Supply and Demand for Primary Care Practitioners: 2013-2025. Bethesda, MD: HRSA; 2016. https:// bhw.hrsa.gov/sites/default/files/bhw/healthworkforce-analysis/research/projections/primary-care-national-projections2013-2025.pdf. Accessed February 11, 2020.

16. Iglehart JK. Health reform, primary care, and graduate medical education. N Engl J Med. 2010;363(6):584-590.

17. Senf JH, Kutob R, Campos-Outcalt D. Which primary care specialty? Factors that relate to a choice of family medicine, internal medicine, combined internal medicine-pediatrics, or pediatrics. Fam Med. 2004;36(2):123-130.
18. Senf JH, Campos-Outcalt D, Kutob R. Factors related to the choice of family medicine: a reassessment and literature review. J Am Board Fam Pract. 2003;16(6):502-512.

19. Kost A, Kardonsky K, Cawse-Lucas J, Sairenji T. Association of family medicine interest at matriculation to medical school and FMIG participation with eventual practice as a family physician. Fam Med. 2019;51(8):682-686

20. Phillips J, Prunuske J, Fitzpatrick L, Mavis B. Initial development and validation of a family medicine attitudes questionnaire. Fam Med. 2018;50(1):47-51.

21. Phillips JP, Prunuske J, Fitzpatrick L, Mavis B. The family medicine attitudes questionnaire: a valid instrument to assess student attitudes toward family medicine. Fam Med. 2019;51(6):493-501.

22. Holden M, Buck E, Clark M, Szauter K, Trumble J. Professional identity formation in medical education: the convergence of multiple domains. HEC Forum. 2012;24(4):245-255. 